\title{
Functional properties of hemostasis in piglets after short-term overheating against the background of corrective action
}

\author{
Vladimir V. Zaitsev ${ }^{1}$, Marina V. Mekhanikova ${ }^{2}$, Svetlana V. Shestakova ${ }^{2}$, and Tatyana P. Ryzhakina ${ }^{2}$ \\ ${ }^{1}$ Samara State Agricultural Academy, Kinel 446442, Samara region, Russia \\ ${ }^{2}$ Vologda State Dairy Farming Academy named after N.V. Vereshchagin, Vologda 160555, Russia
}

\begin{abstract}
Catosal is considered to be a highly effective bio-stimulator. It showed his properties in animals, realizing the stimulation of their tissues and organs. The purpose of this research is to determine the effect of Catosal on hemostatic parameters in piglets that experienced overheating. 58 piglets at the age of 2.5 months, which belonged to a large white breed, were taken into work. All animals as a result of an accidental emergency shutdown of the air conditioning system in the pigsty suffered overheating for 3 hours. These animals were randomly divided into two comparable groups. One was named experimental; the other was called control 1. Pigs of the experimental group (21 heads) received intramuscular injections of $2.5 \mathrm{ml}$ of Catosal daily for 5 consecutive days, from the next day after an overheating episode. The control group 1 consisted of piglets with a total number of 21 . After an overheating episode, they were under the usual conditions of a pigsty and did not receive any effects. In experimental piglets and piglets of the control group 1, all indicators were recorded in the outcome and after 30 days. Control group 2 consisted of 32 completely healthy piglets that were kept under standard conditions of a pigsty for their entire lives. They were examined once. Catosal injections in the observed piglets after overheating led to a decrease in spontaneous and stimulated platelet aggregation to normal levels. Against the background of the use of Catosal in the piglets that made up the experimental group, a weakening of hemocoagulation was found, which improved blood circulation in their tissues. Piglets of control group 1 showed an increase in platelet aggregation and blood coagulation. This had a very negative effect on hemorheology in them and weakened their metabolism. We can assume that in piglets after overheating, in the absence of optimizing effects, hemostasis is activated. This adversely affects the course of microcirculation and inhibits growth. Injections in piglets after overheating of the Catosal lead to a weakening of hemocoagulation and platelet activity to optimum values. This normalizes the course of microcirculation in the internal organs of animals.
\end{abstract}

\section{Introduction}

In the modern world, pig breeding is an actively developing highly efficient branch of agriculture. Now it provides a significant part of the world's population with highly nutritious food products - lard and meat $[1,2]$. In view of the importance of pig breeding, its practitioners set the task of intensifying it by accelerating the rearing of young animals and achieving maximum preservation of the livestock [3]. This is possible to achieve through the use of new approaches to feeding and keeping [4].

Researchers begin to clearly link the viability and productivity of animals with the characteristics of hematological parameters [5]. At the same time, it becomes clear that hemostasis parameters largely affect the state of tissue perfusion and, due to this, the level of anabolism in animals and their productivity [6,7]. Due to the serious physiological significance and the possibility of rapid violation of indicators, they are paying more and more attention in studies under standard and model conditions [8].
The effective way of stimulating the body and enhancing the phenotypic manifestation of genetically determined traits even under negative environmental conditions [9] is considered to be the use of enhanced feeding and bio-stimulators [10]. Their use by mixing in food and the introduction of intramuscular injections can help to increase the productive qualities of pigs [11]. Catosal, which stimulates processes in the blood and tissues, is considered a very effective modern biostimulator in productive animals [12].

Blood parameters always have high liability and therefore are a sensitive marker of functional changes in the body. Blood counts can also respond early to the entry of bio-regulators into the body, which helps to determine their effectiveness. Also, by the dynamics of blood parameters, one can accurately judge changes in the metabolism in the body [13]. At the same time, not only biochemical parameters can change, but also hemostasis indicators. This dynamics is an important consequence of changes in the regulation of the functions of the whole organism [14]. It was very important to elucidate the effect of bio-stimulators on the

Corresponding author: ilmedv1@yandex.ru 
activity of hemostatic mechanisms in piglets caught in adverse environmental conditions. The goal was set in the work: to find out the effect of Catosal on hemostatic parameters in piglets that experienced overheating.

\section{Materials and methods}

This work was carried out in full compliance with ethical standards established by the European Convention for the Protection of Vertebrate Animals and used for scientific experimental purposes (adopted in Strasbourg on March 18, 1986 and confirmed in Strasbourg on June 15, 2006).

The study was conducted on 74 healthy pigs at the age of 2.5 months, which belonged to a large white breed. They were kept in pigsties of the Samara region of Russia. Some of these animals (42 heads) underwent accidental overheating as a result of falling into the environment for 3 hours at $10^{\circ} \mathrm{C}$ above the recognized optimum. These changes in ambient temperature occurred due to a quickly eliminated breakdown of the air conditioning system in the pigsty. The diet of all animals taken into the study was traditional. The animals tested overheating were randomly divided into comparable two groups: experimental and control 1 .

The experimental group included pigs number 21 head. From the next day after the episode of overheating, these animals began to receive Catosal produced by Bayer HealthCare LLC (USA) by intramuscular injection of $2.5 \mathrm{ml}$ per day for 5 days. Control group 1 consisted of 21 piglets. After experiencing overheating, these animals were kept under standard conditions on a standard diet. Piglets in both of these groups were examined twice: immediately after overheating and 10 days after it. Control group 2 consisted of 32 pigs of the same age, completely healthy and never experienced negative influences from the external environment.

Fibrinogen levels were assessed in piglets using the Klaus method. The plasminogen activity was determined by the kinetic method on an FP-901 instrument (LabSystems, Finland) using a chromogenic substrate (Dade Behring, Germany). The concentration of soluble fibrin-monomer complexes in the blood was evaluated by the visual method using reagents manufactured by Technologiya Standart (Russia).

The value of activated partial thromboplastin time was determined using a HumaClot coagulometer (HUMAN GmbH, Germany) using a HemoStat aPTTEL reagent kit. The magnitude of the international normalized ratio was estimated by the Quick method. Platelet aggregation characteristics were determined by a turbodimetric method using a two-channel laser platelet aggregation analyzer (Biola, Russia). Adenosine diphosphate (ADP) $0.5 \mu \mathrm{M}$ was used as an aggregation inducer.

The statistical processing of the results obtained in the work was performed using Student's t-test.

\section{Results}

The performed clarification of the state of hemostasis in piglets undergoing temporary overheating revealed platelet and hemocoagulation mechanisms with a weakening of fibrinolysis (table). In these animals, the activity of their hemostasis in the first study was different from that in control group 2.

Table 1. The dynamics of hemostasis in piglets taken under observation

\begin{tabular}{|l|c|c|c|c|c|}
\hline \multirow{2}{*}{$\begin{array}{l}\text { Registrated } \\
\text { parameters }\end{array}$} & \multicolumn{2}{c|}{ Catosal, $\mathrm{n}=21$} & \multicolumn{2}{c|}{ Control 1, $\mathrm{n}=21$} & $\begin{array}{c}\text { Control 2, } \\
\mathrm{n}=32\end{array}$ \\
\cline { 2 - 5 } & exodus & end of observation & exodus & end of observation & $1.22 \pm 0.09$ \\
\hline $\begin{array}{l}\text { The magnitude of the international } \\
\text { normalized relationship }\end{array}$ & $1.14 \pm 0.14^{*}$ & $1.22 \pm 0.12$ & $1.12 \pm 0.07^{*}$ & $1.13 \pm 0.16^{*}$ & \\
\hline $\begin{array}{l}\text { The duration of the activated partial } \\
\text { thromboplastin time, s }\end{array}$ & $30.4 \pm 0.79^{*}$ & $37.2 \pm 0.63$ & $30.8 \pm 1.03^{*}$ & $26.3 \pm 0.84^{*}$ & $37.1 \pm 0.69$ \\
\hline The concentration of fibrinogen, g/l & $3.4 \pm 0.18^{*}$ & $2.5 \pm 0.15$ & $3.2 \pm 0.22^{*}$ & $3.6 \pm 0.32^{* *}$ & $2.5 \pm 0.23$ \\
\hline $\begin{array}{l}\text { The concentration of soluble fibrin- } \\
\text { monomer complexes, mg/dl }\end{array}$ & $3.3 \pm 0.19^{*}$ & $2.4 \pm 0.17$ & $3.1 \pm 0.26^{*}$ & $3.9 \pm 0.19^{* *}$ & $2.6 \pm 0.82$ \\
\hline Plasminogen activity level, \% & $86.5 \pm 0.32^{*}$ & $94.8 \pm 0.54$ & $85.2 \pm 0.32^{*}$ & $84.4 \pm 0.20^{*}$ & $94.0 \pm 0.57$ \\
\hline $\begin{array}{l}\text { The activity of spontaneous platelet } \\
\text { aggregation, units }\end{array}$ & $1.20 \pm 0.16^{*}$ & $1.60 \pm 0.09$ & $1.24 \pm 0.18^{*}$ & $1.33 \pm 0.10^{* *}$ & $1.01 \pm 0.10$ \\
\hline $\begin{array}{l}\text { The activity of stimulated platelet } \\
\text { aggregation with } 0.5 \mu \mathrm{m} \text { ADP, units }\end{array}$ & $2.46 \pm 0.15^{*}$ & $2.00 \pm 0.23$ & $2.38 \pm 0.16^{*}$ & $2.94 \pm 0.32^{* *}$ & $2.00 \pm 0.21$ \\
\hline
\end{tabular}

Note: statistical differences of indicators from the values of control group 2 : * $-p<0.05, * *-p<0.01$.

By the end of the observation, pigs treated with Catosal showed an increase in activated partial thromboplastin time $(22.4 \%)$, a slight increase in the international normalized ratio $(7.0 \%)$ and plasminogen $(9.6 \%)$ with a decrease in fibrinogen $(36.0 \%)$ and soluble fibrin-monomer complexes (37.5\%), which reached control level 2 by the end of the observation. In animals of control group 1, acceleration of activated partial thromboplastin time $(17.1 \%)$, a slight increase in the international normalized ratio $(0.9 \%)$ and a slight decrease in plasminogen activity $(0.9 \%)$ with an increase in the amount of fibrinogen $(12.5 \%)$ and the amount of fibrin-monomeric complexes in the plasma $(25.8 \%)$, proving the increase in hemostasis is higher than in control group 2.

After 10 days in piglets of the experimental group, platelet aggregation, which occurs spontaneously, was weakened by $20.0 \%$; platelet aggregation, developing on the background of stimulation - by $23.0 \%$. In control animals 1, platelet aggregation spontaneous and ADPstimulated increased, exceeding the outcome by 17.2 and $23.5 \%$, respectively. The difference in platelet 
aggregation level in experimental animals of control group 1 at the time of observation was $33.0 \%$ for spontaneous aggregation $(\mathrm{p}<0.01)$, and stimulated aggregation $-47.0 \%(\mathrm{p}<0.01)$.

\section{Discussion}

Nowadays pig breeding demonstrates a serious need for further accumulation of knowledge on aspects of the physiology of piglets [2]. The study of many issues of the functioning of their internal organs and tissues under the influence of various factors on their bodies is considered very important. The implementation of work on the functioning of the body of piglets is now necessary for practice to rationalize approaches to increasing the profitability of breeding and raising pigs [15].

Systematic studies of the physiology of pigs have not yet given the opportunity to accumulate a sufficient amount of scientific knowledge on the functioning of their basic systems and especially blood. Therefore, it is necessary to evaluate the main mechanisms that provide blood homeostasis in piglets caught in different environmental conditions [16].

It is known that during early ontogenesis in piglets there are fluctuations in various functional parameters under the action of external factors that can impair the functioning of many animal systems. Their influence sometimes violates a number of blood parameters in the conditions of hemocirculation through the capillaries. These biological changes are of great importance, as they can regulate the level of metabolism throughout the body. In addition, this in a certain way affects the basic physiological processes associated with the liquid properties of the blood [17].

It is known that animals have a relationship of age and the state of blood parameters that affect the vital activity of the whole organism [18].

Of great importance is the further serious clarification of any physiological aspects in productive animals under any conditions of keeping and assessing the consequences of environmental influences [19]. Therefore, further physiological observations in piglets and pigs should complement knowledge about their functioning and help to improve approaches to their breeding and feeding [20]. A generalization of the results of these works with their application in practice is planned to intensify modern pig production [21-23].

It is recognized that in mammals, the environment can affect the parameters of hemostasis [24]. Apparently, in the case of negative factors, dysfunctions often appear and pathology arises [25]. It is clear that a decrease in lipid peroxidation activity and an increase in the level of biologically active substances in the blood positively affect the body, activating its growth [26]. It was found that hemostasis activity may decrease [27], having a positive effect on blood rheology [28]. These changes in the blood are associated with improved microcirculation and metabolism with many stimulating effects from the outside [29].
In piglets that experienced overheating, when using Catosal, a decrease in hemostatic function to normal was noted. In control 1, deterioration was found, which led to the end of the observation of significant negative changes in hemostasis, indicating the appearance of prepathology.

The performed study made it possible to find out that the bio-stimulator Catosal positively affects the blood coagulation in piglets after short-term overheating. An important mechanism of this, apparently, is the weakening of the activity of coagulation factors in piglets [30].

Against the background of Catosal, apparently, the formation of thromboplastin and the level of activation of factor XII are weakened in piglets. Moreover, in the body of these piglets against the background of a Catosal, the concentration of fibrinogen and fibrinmonomeric complexes in the blood decreases. In piglets in control group 1, changes of the opposite nature occurred, leading to an increase in the severity of hemocoagulation and a weakening of fibrinolysis.

The administration of a Catosal to animals enhances the antioxidant defense of the animal organism [31, 32], which weakens platelet spontaneous and stimulated aggregation [33]. Obviously, the use of Catosal in piglets increased the amount of cyclic adenosine monophosphate in platelets and reduced the formation of thromboxane $\mathrm{A}_{2}$. These changes restrained platelet aggregate growth in blood in vivo [5].

In animals of control group 1, an increase in platelet aggregation was found, which was largely due to a weakening of the synthesis of cyclic adenosine monophosphate and increased thromboxane $\mathrm{A}_{2}$ generation in them, which increased the number of circulating platelet aggregates in their blood [8].

Researchers have an opinion about the relationship of physical status parameters that reflect the productivity of the animal and as they have hemostatic parameters [34]. In the conducted work were considered some of the early ontogeny of piglets. This allows relying on the obtained data to draw conclusions about the influence of Catosal on the functioning of the piglets that have experienced adverse effects on their body with the explanation of the obtained results with the dynamics of hemostasis.

However, found the possibility of normalizing the state of homeostasis disturbed by adverse environmental impact of using bio-stimulator, may be an important incentive for further research many aspects of stimulation of productivity of piglets, by influencing the activity of hemostasis [30].

\section{Conclusion}

It is clear that blood is the marker of changes in the functional state of the organism. It changes its settings on the intake of many substances. The stronger this background changes the metabolism, the result of a change of blood counts. This is true for hemostasis, which is able to regulate the condition of the animal. It was necessary to assess the impact of Catosal on hemostasis in piglets after their contact with the 
environment with high temperature. Found that overheating in piglets activated hemostasis, which negatively affect the circulation in their bodies and slowed their growth. The use of such animals Catosal reduced the activity of blood coagulation and platelet aggregation, activated their microcirculation and increases the growth of animals.

\section{References}

1. E.S. Tkacheva, S.Yu. Zavalishina, Physiological Features Of Platelet Aggregation In Newborn Piglets, Res. J. of Pharmaceut., Biolog. and Chemical Sci., 9(5), 36-42 (2018)

2. V.I. Maksimov, S.Yu. Zavalishina, A.V. Parakhnevich, E.N. Klimova, N.A. Garbart, A.A. Zabolotnaya, Yu.I. Kovalev, T.Yu. Nikiforova, E.I. Sizoreva, Functional Activity of The Blood Coagulation System Against The Background Of The Influence Of Krezacin And Gamavit In Newborn Piglets Who Underwent Acute Hypoxia, Res. J. of Pharmaceut., Biolog. and Chemical Sci., 9(5), 20372042 (2018)

3. T.I. Glagoleva, I.N. Medvedev, Physiological Features Of Anti-aggregational Control Of Blood Vessels Over The Shaped Elements Of Blood In Calves At The Onset Of Ontogenesis, Res. J. of Pharmaceut., Biolog. and Chemical Sci., 9(5), 440-447 (2018)

4. S.Yu. Zavalishina, Functional Properties Of Coagulation Hemostasis In Calves During The Phase Of Dairy-Vegetative Nutrition, Res. J. of Pharmaceut., Biolog. and Chemical Sci., 9(5), 784-790 (2018)

5. I.N. Medvedev, The Physiological Properties Of Platelets In People 18-35 Years Old, Trained In The Section Of General Physical Training, Res. J. of Pharmaceut., Biolog. and Chemical Sci., 9(6), 1277-1283 (2018)

6. T.I. Glagoleva, S.Yu. Zavalishina, G.S. Mal, O.N. Makurina, I.A. Skorjatina, Physiological Features Of Hemo-coagulation In Sows During Sucking, Res. J. of Pharmaceut., Biolog. and Chemical Sci., 9(4), 29-33 (2018)

7. S.Yu. Zavalishina, Functioning Of Mechanisms Of Hemocoagulation Restriction In Calves At Change Of Methods Of Nutrition, Res. J. of Pharmaceut., Biolog. and Chemical Sci., 9(5), 800-806 (2018)

8. M.P. Kirilov, A new generation of biologically active substances in animal feeding, Feeding farm animals and fodder production, 3, 34-37 (2006)

9. S.Yu. Zavalishina, Deficiency Of Iron As A Cause Of Dysfunction In Calves And Piglets, Res. J. of Pharmaceut., Biolog. and Chemical Sci., 9(5), 978-983 (2018)

10. E.S. Tkacheva, S.Yu. Zavalishina, Physiology of Platelet Hemostasis In Piglets During The Phase Of Newborns, Res. J. of Pharmaceut., Biolog. and Chemical Sci., 9(5), 1912-1918 (2018)
11. V.I. Maksimov, S.Yu. Zavalishina, A.V. Parakhnevich, E.N. Klimova, N.A. Garbart, A.A. Zabolotnaya, Yu.I. Kovalev, T.Yu. Nikiforova, E.I. Sizoreva, Physiological Dynamics Of Microrheological Characteristics Of Erythrocytes In Piglets During The Phase Of Milk Nutrition, Res. J. of Pharmaceut., Biolog. and Chemical Sci., 9(5), 454-459 (2018)

12. A. Sidorenko, Y. Tsygalov, A. Kurdeko, V. Ivanov, S. Petrovskiy, I. Ageev, Catosal helps to realize genetic potential, Pig breeding, 7, 39-41 (2015)

13. E.S. Tkacheva, S.Yu. Zavalishina, Physiological Aspects Of Platelet Aggregation In Piglets Of Milk Nutrition, Res. J. of Pharmaceut., Biolog. and Chemical Sci., 9(5),74-80 (2018)

14. G.M. Bazhov, L.A. Bakhirev, G.A. Urban, Formation of immune function in pregnant and lactating sows when fed biologically active substances, Zootechny, 4, 24-25 (2012)

15. I.N. Medvedev, The Physiological State Of Intravascular Platelet Activity In Young Men Who Had High Normal Blood Pressure, Overweight Or A Combination Of Them And Started Regular Exercise, Res. J. of Pharmaceut., Biolog. and Chemical Sci., 9(6), 1438-1445 (2018)

16. G.S. Mal, N.V. Vorobyeva, A.V. Makhova, I.N. Medvedev, I.I. Fayzullina, Features Of Physical Rehabilitation After Myocardial Infarction, Res. J. of Pharmaceut., Biolog. and Chemical Sci., 9(6), 280-285 (2018)

17. G.S. Mal, E.L. Kharitonov, N.V. Vorobyeva, A.V. Makhova, I.N. Medvedev, Functional Aspects Of Body Resistance, Res. J. of Pharmaceut., Biolog. and Chemical Sci., 9(6), 60-65 (2018)

18. I.V. Amelina, I.N. Medvedev, Evaluation of the dependence of mutagenesis intensity on activity of nucleolus organizer regions of chromosomes in aboriginal population of Kursk region, Bull. of Experim. Biology and Med., 145(1), 68-71 (2008)

19. I.N. Medvedev, T.A. Kumova, Valsartan effects on platelet activity in patients with arterial hypertension and metabolic syndrome, Russ. J. of Cardiol., 3, 66-69 (2007)

20. I.N. Medvedev, O.A. Danilenko, Complex correction of vascular hemostasis in patients with arterial hypertension, metabolic syndrome, and recent ocular vessel occlusion, Russ. J. of Cardiol., 4(84), 15-19 (2010)

21. S.Yu. Zavalishina, Functional Properties Of Anticoagulation And Fibrinolysis In Calves Of Plant Nutrition, Res. J. of Pharmaceut., Biolog. and Chemical Sci., 9(5), 1082-1087 (2018)

22. S.Yu. Zavalishina, Physiology of Vascular Hemostasis In Newborn Calves, Res. J. of Pharmaceut., Biolog. and Chemical Sci., 9(5), 1037-1044 (2018)

23. S.Yu. Zavalishina, Functional Properties of Hemocoagulation In Calves Of Dairy Nutrition, 
Res. J. of Pharmaceut., Biolog. and Chemical Sci., 9(5), 1016-1022 (2018)

24. S.Yu. Zavalishina, Physiological Features of Vascular Hemostasis In Calves Of Dairy-Vegetative Food, Res. J. of Pharmaceut., Biolog. and Chemical Sci., 9(5), 1137-1143 (2018)

25. S.Yu. Zavalishina, Functional Antiaggregatory Properties Of Blood Vessels In Calves During Transition From Dairy To Plant Type Of Nutrition, Res. J. of Pharmaceut., Biolog. and Chemical Sci., 9(5), 1110-1116 (2018)

26. S.Yu. Zavalishina, Functioning Of Platelets In Milk And Vegetable Nutrition Calves, Res. J. of Pharmaceut., Biolog. and Chemical Sci., 9(5), 943-949 (2018)

27. I.N. Medvedev, T.A. Kumova, Angiotensin II receptor inhibitors: role and place in arterial hypertension and metabolic syndrome treatment, Russ. J. of Cardiol., 5, 97-99 (2007)

28. Ju.L. Oshurkova, I.N. Medvedev, Physiological Indicators Of Platelets In Ayrshire Calves During The Dairy Feeding Phase, Res. J. of Pharmaceut., Biolog. and Chemical Sci., 9(6), 171-176 (2018)
29. S.Yu. Zavalishina, Physiological Mechanisms Of Hemostasis In Living Organisms, Res. J. of Pharmaceut., Biolog. and Chemical Sci., 9(5), 629-634 (2018)

30. Ju.L. Oshurkova, I.N. Medvedev, Functional Features Of Platelets In Newborn Calves Ayrshire Breed, Res. J. of Pharmaceut., Biolog. and Chemical Sci., 9(6), 313-318 (2018)

31. S.Yu. Zavalishina, Functional Activity Of Plasma Hemostasis In Neonatal Calves With Iron Deficiency, Who Received Ferroglucin And Glycopin, Res. J. of Pharmaceut., Biolog. and Chemical Sci., 9(5), 1186-1191 (2018)

32. I.N. Medvedev, T.A. Kumova, Reduced platelet aggregation in losartan-treated patients with arterial hypertension and metabolic syndrome, Russ. J. of Cardiol., 1, 40-42 (2008)

33. S.Yu. Zavalishina, Functional Features Of Platelets In Newborn Calves With Iron Deficiency, Res. J. of Pharmaceut., Biolog. and Chemical Sci., 9(5), 1153-1158 (2018)

34. I.N. Medvedev, O.V. Gamolina, Lisinopril effects on platelet activity in patients with arterial hypertension and impaired glucose tolerance, Russ. J. of Cardiol., 3, 45-48 (2008) 